\title{
Российский рынок овощебахчевых культур и баланс производства и потребления продукции
}

\section{The Russian market of vegetables and melons and a balance of production and consumption of products}

\section{Сирота С.М., Пинчук Е.В., Шевченко Т.Е.}

\section{Аннотация}

Свежие овощи и фрукты должны быть обязательной частью рациона питания современного человека. Овощи - основные поставщики биологически активных и минеральных веществ, фитонутриентов и антиоксидантов, отвечающих за поддержание здоровья и хорошего самочувствия человека. Однако большая часть взрослого населения стран мира, в том числе и России, мало прислушивается к рекомендациям Всемирной организации здравоохранения (ВО3) и не уделяет большого внимания правильному питанию и своему здоровью. Цель работы: проанализировать производство и потребление овощебахчевой продукции в России. В ходе исследования использованы материалы официальной статистики и ряда российских и зарубежных аналитических компаний, на основе чего сделаны расчеты и выводы. Разница между физиологически минимальной, рекомендованной и фактической нормами потребления овощебахчевой продукции показывает, что большинство людей не получают достаточного их количества. Реальное потребление овощей находится примерно на уровне 50-60 кг на душу населения в год. 10\% россиян приближается к международному уровню потребления овощей и фруктов, 40\% потребляют вдвое меньше рекомендуемой нормы, уровень потребления остальной части населения низок, что связано в том числе со снижением доходов населения. Обеспечение уровня потребления овощей населением до норм, рекомендованных научной медициной, - одна из важных государственных задач, затрагивающих аспекты здравоохранения, устойчивого развития отраслей овощеводства и семеноводства и развития сельских территорий, импортозамещения и в целом обеспечения продовольственной безопасности страны. Сделан вывод о том, что официальные данные Росстата, а соответственно и информация оперирующих этими данными многих аналитических агентств, занимающихся исследованием рынка овощей, не отражают реальную картину потребления овощей россиянами. Даны рекомендации Министерству здравоохранения и научным учреждениям РАН по разработке программ по пропаганде потребления овощей и формировании ведомством заказа для Минсельхоза РФ на их производство.

Ключевые слова: сельское хозяйство, овощеводство, потребление овощей, овощебахчевая продукция, импортозамещение, семеноводство.

Для цитирования: Сирота С.М., Пинчук Е.В., Шевченко Т.Е. Реалии российского рынка овощебахчевых культур в разрезе баланса производства и потребления продукции // Картофель и овощи. 2020. №4. С. 3-9. https://doi.org/10.25630/PAV.2020.93.16.001
Sirota S.M., Pinchuk E.V., Shevchenko T.E.

Abstract

Fresh vegetables and fruits should be a mandatory part of the diet of modern people. Vegetables are the main suppliers of biologically active and mineral substances, phytonutrients and antioxidants that are responsible for maintaining human health. However, most of the adult population of the world, including Russia, does not pay much attention to the recommendations of the world health organization and does not pay much attention to proper nutrition and their health. The purpose of our research: to analyze production and consumption of vegetable and fruit products in Russia. In the course of the research, the authors used the materials of official statistics and a number of Russian and foreign analytical companies, on the basis of which they made calculations and conclusions. The difference between the physiologically minimal, recommended and actual norms of consumption of melon products shows that most people do not get enough of them. The actual consumption of vegetables is approximately $50-60 \mathrm{~kg}$ per capita per year. $10 \%$ of Russians are approaching the international level of consumption of vegetables and fruits, $40 \%$ consume half the recommended norm, and the level of consumption of the rest of the population is low, this is due to a decrease in the population's income. Ensuring the level of consumption of vegetables by the population to the standards recommended by scientific medicine is one of the important state tasks that affect the health aspects, sustainable development of vegetable and seed growing industries and rural development, import substitution and overall food security of the country. It is concluded that the official data of Rosstat, and consequently the information of many analytical agencies that use this data to study the vegetable market, do not reflect the real picture of vegetable consumption by Russians. Recommendations are given to the Ministry of health and scientific institutions of the Russian Academy of Sciences on developing programs to promote the consumption of vegetables and forming an order for the Ministry of agriculture of the Russian Federation for their production.

Key words: agriculture, vegetable production, consumption of vegetables, vegetable products, import substitution, seed production.

For citing: Sirota S.M., Pinchuk E.V., Shevchenko T.E. Realities of the Russian market of vegetables melons in the context of the balance of production and consumption of products. Potato and vegetables. 2020. No4. Pp. 3-9. https://doi.org/10.25630/PAV.2020.93.16.001 (In Russ.) вежие овощи и фрукты - неотъемлемая часть рациона современного человека Показатели потребления свежих овощей, зеленных культур и фруктов как нельзя лучше характеризуют степень здоровья общества, благосостояния населения и развитости социума в целом.
Вместе с тем, потребление столь важной продукции во многих странах мира крайне низкое. Новое исследование, которое опубликовано в английском журнале British Journal of Nutrition показало, что большинству людей по всему миру следует увеличить потребление фруктов и овощей, по крайней мере, в два раза, чтобы достичь минимума, рекомендованного ВОЗ - пять порций, или 400 г в день. Кроме того, большая часть взрослого населения (от 60 до 87\% в исследованных тринадцати регионах мира) не следует данной рекомендации и не уделяет большого внимания важности питания и своему здоровью $[1,2]$. Между тем из- 
вестно, что систематическое введение в рацион питания овощей способствует профилактике и лечению многих заболеваний. Учеными Государственного онкологического центра Японии доказано, что регулярное потребление желто-зеленых овощей (петрушки, салата, горчицы, укропа и др.) снижает в два раза риск заболевания раком даже при систематическом курении, употреблении алкоголя, калорийной и жирной пищи [3]. По мнению доктора Нила Оушене из Британского университета Лидса, всего одна дополнительная порция овощей или фруктов в день способна повлиять на психическое благополучие так же, как восемь дополнительных десятиминутных прогулок в месяц [4].

Разница между рекомендованной и фактической порциями фруктов и овощей показывает, что большинство людей не получает достаточного количества фитонутриентов и органических веществ, необходимых для поддержания здоровья и хорошего самочувствия. В исследовании говорится, что потребление пищи, богатой фитонутриентами, помогает людям укрепить зрение и кости, здоровье сердца, иммунную систему и улучшить работу головного мозга. Многие фитонутриенты - сильные антиоксиданты, которые защищают клетки организма от токсинов.

Фитонутриенты - это натуральные питательные вещества, придающие плодам яркую окраску. Огромное количество научных работ подтверждает их способность снижать риск развития сердечно-сосудистых заболеваний, рака и диабета. Так, люди, съедающие от 5 до 7 порций фруктов и овощей в день (одна порция - 100-200 г), на 50\% снижают для себя риск развития инфарктов и инсультов. При этом лучше всего, если овощи и фрукты будут разной окраски (цвет растения зависит от содержания тех или иных минералов и фитонутриентов, которыми оно богато). Например, в зеленых и оранжевых овощах содержатся флавоноиды - природные антиоксиданты, защищающие организм от старения.

Овощи - основные поставщики биологически активных и минеральных веществ. Организм человека не способен синтезировать антиоксиданты, поэтому в современных экологических условиях рацион должен в обязательном порядке содержать биологические вещества антиоксидантного ряда, в том числе йод и селен, обладающие антиоксидант- ным и иммуномодулирующим действием. В настоящее время у населения России очень остро стоит вопрос дефицита йода. При этом более в 70\% густонаселенных территорий страны наблюдается недостаток йода в воде, почве и продуктах питания местного происхождения, ведь главные природные источники этого элемента - морепродукты. По данным Эндокринологического научного центра РАМН, среднестатистическое потребление йода в России в 1,5-2 раза меньше суточной потребности. Альтернативными источниками йода и селена могут служить овощи [5].

Малоподвижный образ жизни, стрессы и ухудшающаяся экология требуют для современного человека сбалансированного питания, богатого источниками макро-, мезо- и микроэлементов, витаминов и антиоксидантов, столь необходимых для профилактики болезней и здоровья организма человека.

\section{Условия, материал и методы} исследований

В ходе исследования использованы материалы официальной статистики и ряда российских и зарубежных аналитических компаний. При анализе использовали логический метод с элементами синтеза, аналогии, прогнозирования, сопоставлений, системно-структурный анализ, на основе чего сделаны расчеты и выводы.

\section{Результаты исследований}

В мире уделяется важное значение качеству питания и не случайно в системе показателей уровня жизни в международной статистике $\mathrm{OOH}$ (разработана в 1978 году), включающей 12 основных групп показателей, потребление продовольственных товаров, куда входят и овощи, находится на третьем месте.

Критерием для оценки уровня потребления населением овощей международным сообществом (ВО3) приняты два показателя: физиологически минимальная норма потребления на душу населения - 146 кг/год (400 г/сут.) и рекомендуемая норма потребления на душу населения 219 кг/год (600 г/сут.).

В Россиитакже Министерством экономики РФ в 1992 году разработана система «Основные показатели уровня жизни населения в условиях рыночной экономики». Она состоит из семи разделов, охватывающих 40 показателей и показатель «Потребление населением основных продуктов питания» находится в треть- ем разделе, а по общему списку на 16 месте.

К сожалению, в ведомствах исполнительной власти до сих пор нет единого представления о значимости овощей в питании и, соответственно, норм их потребления. Так, нормы питания в России закреплены приказом Минздрава от 19.08.2016 № 614, где применена норма потребления овощей - 140 кг/год (380 г/сут). Однако в своих отчетах и прогнозах Минсельхоз РФ использует собственную норму потребления овощей - 120 кг/год на душу населения.

В силу каких причин исполнительной властью принижается роль овощей в рационе питания нам не известно, однако из документов видно, что уровень минимальной нормы потребления овощей ниже в сравнении с международным стандартом, а ведь за этим стоит здоровье подрастающего поколения, взрослого населения и нации в целом. Наконец, отрасль лишена драйвера развития.

Новые нормы потребления овощей ниже и тех, которые были разработаны в свое время Институтом питания РАМН при СССР - 145 кг/год на душу населения. Следует также привести один исторический документ: Приказ НКО СССР № 232 от 12 июля 1941 года «Об объявлении норм продовольственного пайка для военнопленных» за подписью заместителя народного комиссара обороны СССР генерала армии Г.К. Жукова: наряду с прочими продуктами, норма суточного пайка для военнопленных немцев установлена, согласно приказа, по картофелю и овощам - 500 г/сут. В том же приказе, норма продовольственного пайка для больных и истощенных военнопленных немцев определена по картофелю и овощам 600 г/сут, а противоцинготный паек предусматривал дополнительно к суточному рациону еще 200 г картофеля и овощей. При этом надо принять во внимание, что СССР отказался от подписания Соглашения от 27 июля 1929 года относительно обращения с военнопленными.

По словам директора НИИ Питания РАМН, академика Виктора Тутельяна, есть всего лишь два закона здорового питания: «Первый закон - соответствие энергетической ценности рациона энергетическим тратам. Например, одно пирожное или сарделька - это два часа ходьбы или час бега. Второй закон - необходимо получить с пищей все необходимые компоненты (это около 200 соединений). Причем больше поло- 
вины из них незаменимые. Если мы их не получим извне, то выработаться у нас они не могут. Длительное нарушение этих законов приводит к болезни. Очень серьезное и длительное - к смерти» [1].

В связи с этим очевидна необходимость систематического употребления свежих овощей в объемах, рекомендованные официальной медициной и для России это особенно актуально, поскольку на большей части ее территории преобладает резкоконтинентальный климат и продолжительная зима, требующие крепкого здоровья и повышенного иммунитета.

Однако по данным НИИ питания РАМН, сегодня в общей структуре заболеваемости россиян 30-50\% составляют так называемые алиментарно-зависимые заболевания, т.е. напрямую связанные с недополучением с пищей полезных веществ фитонутриентов. Потребность в калориях уменьшилась за последние 30-40 лет на 1200-1500 ккал. Притом, что потребность в микроэлементах, витаминах не изменилась или увеличилась на 10\%. Проблема дефицита потребления овощей характерна не только в России. По данным ВОЗ, дефицит фитонутриентов, витаминов и минералов испытывают 1/3 населения планеты. ВОЗ даже называет эту причин одной из главных причин смертности в мире [6].

Согласно официальной статистике россияне не доедают до рекомендуемой нормы потребления овощей чуть более 20\%. Закономерно возникает вопрос, почему тогда такой большой процент заболеваемости от недополучения в рационе овощей?

Росстат, а также многие аналитические агентства занимаются исследованием рынка овощей, большинство которых зачастую используют данные Росстата и оперируют ими. В то же время, есть агентства, которые ведут собственные исследования и получают результаты, значительно отличающиеся от Росстата. В частности, исследованиями ком- пании «Амико» установлено, что россияне употребляют всего 63 кг свежих овощей на душу населения в год. По данным компании Intesco Researh Group: «... в натуральном выражении картина несколько отличается. В Башкирии потребление овощей на человека составляет 3 кг/мес., в Тюменской области - 3,4 кг/мес., в Краснодарском крае и Ростовской области - 4 и 4,8 кг/мес., соответственно (в расчете на год 36-57,6 кг на душу населения)». Генеральный директор некоммерческого партнерства «Фруктово-овощной альянс» Георгий Чистяков утверждает, что в настоящее время только $10 \%$ россиян приближается к международному уровню потребления овощей и фруктов, 40\% потребляют вдвое меньше рекомендуемой нормы, уровень потребления остальной части населения катастрофически низок [7].

Среднестатистический россиянин съедает в год не более 1/3 необходимого количества овощей и фруктов, причем потребление значительно зависит от места проживания: в регионах - 32 кг на душу населения в год, в Москве - 60 кг. Для сравнения, в США - 126, Канаде - 126, Австралии - 135 и Китае - 50 кг на душу населения в год [8].

Россия по уровню потребления некоторых видов овощей и особенно фруктов далеко отстает от многих стран мира. В России среднее потребление фруктов и овощей составляет менее 300 г в день, что намного ниже минимальной физиологической нормы, рекомендуемой ВОЗ и современными диетологами. Проведенные в России исследования доказывают, что более 2/3 жителей Москвы и более 3/4 в Архангельске и Мурманске не потребляют рекомендуемое количество фруктов и овощей, и, следовательно, имеют повышенный риск развития различных заболеваний [9].

Культура питания в России далека от того, чтобы придерживаться рациона, в котором присутствуют в достаточном количестве овощи, с целью профилактики болезней, скорее овощи служат украшением стола и могут быть лакомством. Согласно исследованиям компании CSR Research, потребление сырых овощей менее частое, чем фруктов. 10\% москвичей употребляют их не каждую неделю. Основная масса потребляет менее десяти различных овощей в неделю. Активные потребители сырых овощей сосредоточены среди молодежи: 45\% в группе до 25 лет потребляют более 11 овощей в неделю, 43\% в группе от 25 до 35 лет. Среди пожилого населения доля с таким активным потреблением составляет лишь $10 \%$. Значительная доля свежих овощей в рационе отличает потребление высокодоходной группы - 34\% представителей этой группы указали на потребление более 15 овощей в неделю. По вкусовым предпочтениям безусловные фавориты среди овощей - помидоры и огурцы (42\% москвичей). Среди молодежи до 25 лет помидоры и огурцы назвали среди любимых свыше 55\%. Вторую группу составляют баклажаны и сладкий перец (20\%), которые пользуются популярностью в первую очередь среди населения Москвы среднего возраста. Огурцы, помидоры, редис, баклажаны и цветная капуста оцениваются как относительно дорогие овощи, т.к. пользуются повышенной популярностью среди обеспеченных групп. На уровне 10\% и менее среди любимых овощей были названы цветная капуста, зеленый салат, чеснок, редис, капуста брокколи. Несмотря на лидерство по вкусовым предпочтениям, огурцы и помидоры по потреблению находятся далеко позади недорогих овощей - картофеля, моркови, лука и капусты. Огурцы потребляли 38\% москвичей, помидоры - 31\%. Баклажаны, цветную капусту и сладкий перец часто включают в свой рацион лишь 5-8\% москвичей. Такая ситуация характерна особенно для ранневесеннего периода. Активное потребление овощей предполагает и большее разнообразие рациона. При этом 57\% москви-

Таблица 1. Валовой сбор овощей в 1992-2018 годах, тыс. т [13, 14]

\begin{tabular}{|l|c|c|c|c|c|c|c|c|c|}
\hline \multicolumn{1}{|c|}{ Тип хозяйства } & \multicolumn{3}{c|}{ Год } \\
\hline С.-х. организации (открытый грунт) & 1992 & 2000 & 2005 & 2010 & 2014 & 2015 & 2016 & 2017 & 2018 \\
\hline Хозяйства населения & 4500 & 2500 & 2100 & 2100 & 2600 & 2900 & 3100 & 3500 & 3600 \\
\hline КФХ & 5500 & 8100 & 8400 & 7500 & 8200 & 7900 & 7700 & 7500 & 7500 \\
\hline Всего по открытому грунту & 78 & 263 & 781 & 1422 & 2089 & 2396 & 2381 & 2586 & 2559 \\
\hline Всего по защищенному грунту (с.-х. организации) & - & - & - & - & 690,8 & 717,7 & 813,7 & 922,2 & 930,0 \\
\hline
\end{tabular}


Таблица 2. Импорт овощей в Россию в 2013-2018 годах $[15,16]$

\begin{tabular}{|c|c|c|c|c|c|c|}
\hline \multicolumn{1}{|c|}{ Показатель } & \multicolumn{6}{|c|}{ Год } \\
\cline { 1 - 8 } & 2013 & 2014 & 2015 & 2016 & 2017 & 2018 \\
\hline Импорт овощей, тыс. т & 2551,6 & 2578,7 & 1967,5 & 1445,0 & 1821,9 & 1788,4 \\
\hline Импорт овощей, \$ млн & 2549,6 & 2460,1 & 1558,2 & 1203,9 & 1470,0 & 1535,9 \\
\hline
\end{tabular}

чей считают, что потребляют достаточно свежих овощей. В особенности, это относится к активным потребителям - среди молодежи до 25 лет удовлетворены 83\%, среди тех, кто потребляет более 11 овощей - 73\%. Среди низкодоходных слоев населения удовлетворенность на уровне 50\%. [10]. Среди большинства населения спросом пользуются в основном недорогие овощи - картофель, морковь, свекла.

Вышеприведенная статистика подтверждается данными исследования, проведенного компанией FDFgroup. Москвичи регулярно покупают свежие овощи и фрукты, но удовлетворенность качеством предлагаемой продукции достаточно низка. Более $90 \%$ москвичей в возрасте от 18 до 65 лет приобретают свежие овощи и фрукты как минимум раз в месяц. Две трети жителей столицы совершают такие покупки чаще раза в неделю и лишь 8\% - приобретают эту продукцию реже раза в месяц или вообще ее не покупают. Согласно результатам опроса, проводившегося в июне, в весенне-летний период для жителей столицы характерно следующее потребление овощей и фруктов. Наиболее популярные овощи - картофель, огурцы, репчатый лук, помидоры, морковь, капуста и зеленные культуры. Картофель регулярно покупают 78\% москвичей, огурцы и репчатый лук - около $60 \%$, помидоры - 56\%, а морковь, капусту и зелень - немногим менее $50 \%$ опрошенных [11].

Следует отметить, что экономическая ситуация в стране далеко не благоприятна активному потреблению овощей, так, начиная с 2013 года, реальные доходы населения за пять лет упали на $11 \%$, следует из данных Росстата (рис.). По данным того же ведомства, в начале 2019 года реальные доходы россиян резко ушли в минус - по итогам первого квартала показатель сократился на 2,3\%.

Выводы Росстата о неблагоприятном экономическом климате в стране подтверждают частные исследовательские агентства: Татьяна Малева (директор Института социального анализа и прогнозирования ян» [12]. нам Росстат. сколько сценариев: кость рынка овощей). селение России $+10 \%$ (потери) $=$ 17762985 т.

Вариант 3. Исходя из фактического потребления овощей, 60 кг/год x 146801527 человек население России $+10 \%$ (потери) $=$ 9688901,2 т (фактическая емкость рынка овощей).

Каков же сценарий состояния РАНХ и ГС), Игорь Николаев (директор Института стратегического анализа ФБК antThornten). По утверждению Юлии Старостиной, «По состоянию на конец 2018 года, за чертой бедности живут 18,9 млн росси-

Учитывая культуру потребления (овощи не являются у россиян продуктами первой необходимости, и стоят они недешево), а также отсутствие у людей средств, можно заключить, что реальное потребление овощей в России катастрофически низкое. И нельзя не согласиться с результатами исследований многих аналитических агентств - реальное потребление овощей находится примерно на уровне 50-60 кг на душу населения в год, а не 110 , как дает

Для Минсельхоза РФ, Минздрава РФ, вероятно, важно, сколько же овощей необходимо реально производить, чтобы обеспечить сбыт продукции и удовлетворить потребность населения в витаминной продукции и здесь, на наш взгляд, возможно не-

Вариант 1. Исходя из нормы потребления овощей, установленной приказом Минздрава от 19.08.2016 № 614,- 140 кг/год x 146801527 человек население России + $10 \%$ (потери) $=22607435$ т (потенциальная ем-

Вариант 2. Исходя из данных Росстата, потребление овощей 110 кг/год x 146801527 человек на-

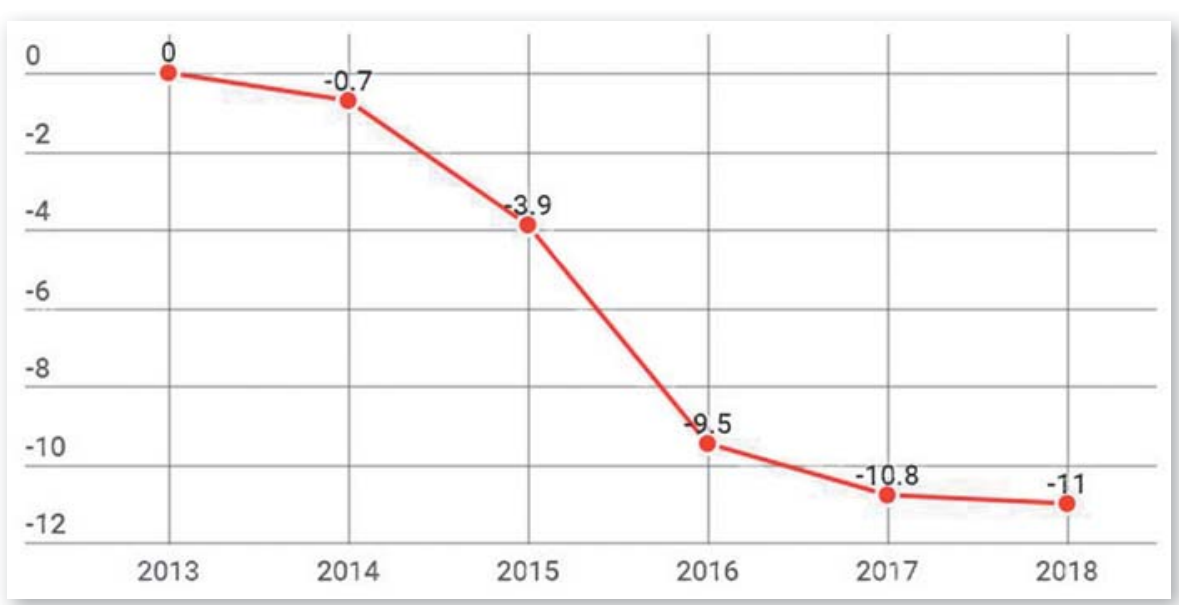

Динамика падения реальных доходов с 2013 по 2018 год овощеводства и потребительского рынка может быть построен из полученных нами данных о емкости рынка овощей в России? В табл. 1, 2 представлены источники поступления продукции на рынок. На сегодня, по данным Росстата, основной объем продукции на рынок поступает из открытого грунта - 13569 тыс. т овощей (2018 год), 930 тыс. т - из защищенного, и довольно значительная доля овощей поступает по импорту 1788,4 тыс. т.

Перспективы организации сбыта в РФ по достоинству оценили уже практически все ведущие производители овощей и фруктов из разных частей света [2]. Рост объемов импорта, по оценке компании «Технологии Роста», составляет 2-5\% в год в сегменте яблок, томатов и огурцов. В сегменте сладкого перца, салатов, груш и клубники рост объемов импорта достигает 20-30\% в год. Основные потоки импорта свежих овощей и фруктов в РФ идут с января по май, когда цены и спрос на них максимальны. К сожалению, отечественные производители не могут составить сколько-нибудь значимую конкуренцию мировому импорту. Заявленная государственная подде2020 годы пока не дала положительных результатов, а вступление в ВТО еще больше открыло границы зарубежным поставкам. ржка с. - х. производителей на 2013- 
Таблица 3. Экспорт овощей из России [16]

\begin{tabular}{|c|c|c|c|c|c|c|}
\hline \multirow{2}{*}{ Показатель } & \multicolumn{6}{|c|}{ Год } \\
\cline { 1 - 7 } & 2013 & 2014 & 2015 & 2016 & 2017 & 2018 \\
\hline Экспорт овощей, тыс. т & 589,0 & 680,0 & 1197,0 & 1318,0 & 1563,0 & 1685,0 \\
\hline Экспорт овощей, \$ млн & 249,0 & 247,0 & 403,0 & 473,0 & 494,0 & 406,0 \\
\hline
\end{tabular}

Итого: из всех источников на рынок поступает 16287,4 тыс. т овощей.

Как распределяется по потребителям эта продукция? Хочется отметить, прежде всего, как положительный фактор и достижение отрасли овощеводства, формирование нового канала сбыта - в последние годы в России появился экспорт овощей, и, в частности, в 2018 году на экспорт поставлено 1685 тыс. т свежей продукции (табл. 3)

Итого, с учетом экспорта на внутреннее потребление, остается около 14439,9 тыс. т овощей. На основании данных Росстата и данных, полученных нами, мы сделали попытку рассчитать баланс прихода и расхода овощей. Как видно из табл. 4, из четырех представленных вариантов расчета - три, показывают дефицит производства овощей.

И только вариант с использованием показателя фактического потребления овощей показал положительное сальдо - избыток более 5 млн т овощей. Очевидно, что ежегодное перепроизводство овощей в таких объемах не могло не привлечь внимания производителей товарной продукции и общественности и вывод может быть только один - этих овощей нет, как нет перепроизводства.

Данные Росстата по производству товарных овощей в с.- х. организациях, КФХ, защищенном грунте, в с. - х. организациях основываются на формах обязательной отчетности 29-сх и 4-сх. Информация о ввозе овощей также основана на обязательной отчетности ФТС и вместе не вызывает сомнения в достоверности. В то же время, графа «хозяйства населения», где находится бо- лее половины овощей, произведенных в России, не может не вызывать сомнений, поскольку формируется умножением среднестатистического выхода овощей с одного хозяйства на их общее количество в стране, что не отражает реального состояния домохозяйств. Поэтому избыток овощей (строка 3, табл. 4) в размере более 5 млн т, есть ни что иное как приписки Росстата в объемах производства овощей, а возможный дефицит (строка 4, табл. 4), есть доля, которую можно отнести на хозяйства населения, которую они вносят в общее производство и потребление овощей в стране.

\section{Выводы}

Таким образом, фактическое потребление овощей в Российской Федерации не соответствует физиологически минимальным показателям, рекомендованным Всемирной организацией здравоохранения (146 кг/год на человека) и составляет около $40 \%$ от нормы. Обеспечение уровня потребления овощей населением до норм, рекомендованных научной медициной,- одна из важных и приоритетных государственных задач для улучшения здоровья, увеличения продолжительности жизни населения и обеспечения продовольственной безопасности, что отвечает Доктрине продовольственной безопасности РФ от 21 января 2020 года. Однако необходимо учитывать, что для большей части населения в обозримом будущем единственным ключевым фактором выбора овощебахчевой продукции будет цена. В связи со снижением покупательской способности населения, снижается и потребление разнообразных све- жих овощей как высокостоимостной категории товаров, когда потребитель не ставит в приоритет нормы, рекомендованные официальной медициной, учитывая лишь стоимость. Тем самым, также возникает снижение сбыта овощной продукции. Официальные данные Росстата, а соответственно и информация оперирующих этими данными многих аналитических агентств, занимающихся исследованием рынка овощей, не отражают реальную картину потребления овощей россиянами. Методика расчета Росстатом фактического потребления овощебахчевой продукции нуждается в серьезной корректировке. По мнению авторов, преувеличена роль хозяйств населения и их доля в формировании емкости рынка товарных овощей. Данные Росстата свидетельствуют о дефиците овощей, который, вероятно, восполняется нелегальными поставками из-за рубежа. Улучшение ситуации с обеспеченностью населения России овощами видится авторам в разработке Министерством здравоохранения и научными учреждениями РАН программ по пропаганде потребления овощей и формировании ведомством заказа для Минсельхоза РФ на их производство. Минсельхозу, в соответствии с заказом, необходимо принять программу по восстановлению отечественного овощеводства и его инфраструктуры, выступить в качестве планирующей организации по производству овощной и бахчевой продукции в объемах и в ассортименте на основе квотирования производства продукции в разрезе регионов и организаций.

Сегодня торговые сети («Пятерочка», «Магнит», «Ашан», «Глобус», «Перекресток» и т.д.) стали по сути единственным каналом связи «производитель - потребитель» и при этом они вносят львиную долю в увеличение цены на овощи, зачастую на основе надуманных причин

Таблица 4. Баланс овощной продукции в России (по данным 2018 года)

\begin{tabular}{|c|c|c|c|c|c|c|c|c|}
\hline \multicolumn{6}{|c|}{ Источники поступления овощей на рынок, тыс. т } & \multicolumn{2}{|c|}{ Расход, тыс. т } & \multirow{2}{*}{ Баланс } \\
\hline $\begin{array}{c}\text { C.-х. } \\
\text { организации }\end{array}$ & $\begin{array}{l}\text { Хозяйства } \\
\text { населения }\end{array}$ & КФX & $\begin{array}{l}\text { Защищен- } \\
\text { ный грунт }\end{array}$ & Импорт & Всего & $\begin{array}{c}\text { Потребление } \\
\text { населением }\end{array}$ & Экспорт & \\
\hline 3600,0 & 7500,0 & 2559,0 & 930,0 & 1788,4 & 16377,4 & $17763,0^{*}$ & 1685,0 & $-3070,6$ \\
\hline 3600,0 & 7500,0 & 2559,0 & 930,0 & 1788,4 & 16377,4 & $22480,0^{* *}$ & 1685,0 & $-7787,6$ \\
\hline 3600,0 & 7500,0 & 2559,0 & 930 & 1788,4 & 16377,4 & $9636,0^{\star \star \star}$ & 1685,0 & $+5056,4$ \\
\hline 3600,0 & - & 2559,0 & 930,0 & 1788,4 & 8877,4 & $9636,0^{\star \star \star}$ & 1685,0 & $-2443,6$ \\
\hline \multicolumn{9}{|c|}{ * потребление овощей по данным Росстата, 110 кг/на душу населения в год } \\
\hline \multicolumn{9}{|c|}{ ** потребление овощей в соответствии с медицинской нормой, 140 кг/на душу населения в год } \\
\hline \multicolumn{9}{|c|}{ *** потребление овощей фактическое, 60 кг/на душу населения в год } \\
\hline
\end{tabular}


создают препятствия для поставки овощной продукции производителями на свои прилавки, а также возврата продукции, вынуждая их платить штрафные санкции. Торговые сети ведут себя, как и подобает монополистам, следовательно, государству, в лице правительства, необходимо обратить внимание на важное звено в обеспечении населения продуктами питания и навести порядок.

Сегодня отмечается значительная зависимость отечественного овощеводства от импорта семян овощных и бахчевых культур. Основа овощеводства и бахчеводства - се- меноводство, находится в упадке, следовательно, предпосылкой для восстановления отрасли авторы видят принятие Закона «О семеноводстве» в редакции 1993 года, что позволит снизить зависимость России от зарубежных поставок семян.

\section{Библиографический список}

1.Современная еда - главная причина смертельных заболеваний[Электронный ресурc] URL: http://www.moscowuniversityclub. ru/home.asp?artld=10176. Дата обращения: 26.02.2020.

2.Сирота С.М., Кононков П.Ф. Состояние производства, потребления овощей и семеноводства овощных культур. Федеральный справочник. М., 2009. С. 303-310.

3.Гиль Л.С., Пашковский А.И., Сулима Л.Т. Современное овощеводство закрытого и открытого грунта. Практическое руководство. Житомир: Рута, 2012. 468 с.

4.Евгеньева Н. Ученые назвали неожиданные последствия отказа от овощей [Электронный ресурc] URL: https://www. msn.com/ru-ru/foodanddrink/foodculture. Дата обращения: 26.02.2020.

5.Лудилов В.А. и др. Пищевая ценность зеленных овощных культур семейства Капустные // Сб. науч. тр. по овощ. и бахч. (к 80-летию со дня основания ГНУ ВНИИО РАСХН). М., 2011. С. 401-405.

6.Информационный бюллетень ВОЗ [Электронный ресурс] URL: https://www.who.int. Дата обращения: 26.02.2020.

7.Россияне потребляют в три раза меньше фруктов, чем нужно [Электронный ресурс] URL: https://www.newsru.com/ finance/09jun2002/fruits.html. Дата обращения: 26.02.2020.

8. Известия» [Электронный ресурc] URL: https://www.iz.ru. Дата обращения: 26.02.2020.

9.Потребление овощей и фруктов в России и странах Европы [Электронный ресурc] URL: http://go-veg.ru/vegetables-norm. Дата обращения: 26.02.2020.

10.Потребление свежих овощей и фруктов [Электронный реcypc] URL: https://www.marketing.spb.ru/mr/food. Дата обращения: 26.02.2020.

11.Гнедков С., Морозова А. Обзор московского рынка овощей и фруктов // Российский продовольственный рынок [Электронный peсурc] URL: http://www.foodmarket.spb.ru/ archive.php. Дата обращения: 26.02.2020.

12.Школа инвестора [Электронный ресурc] URL: http:// investorschool.ru/economica. Дата обращения: 26.02.2020.

13.Россия в цифрах. 2019 год [Электронный ресурс] URL: http://www.gks.ru/wps/wcm/connect/rosstat_main/rosstat/ru/ statistics/publications/catalog. Дата обращения: 26.02.2020.

14.Дятловская Е. В 2019 году урожай тепличных овощей вырастет до 1,3 млн тонн [Электронный ресурc] URL: https://www. agroinvestor.ru/analytics/news. Дата обращения: 26.02.2020.

15.Показатели, характеризующие импортозамещение в России [Электронный ресурc] URL: http://www.gks.ru/wps/wcm/ connect/rosstat main/rosstat/ru. Дата обращения: 26.02.2020.

16.Таможенная статистика внешней торговли [Электронный pecypc] URL: http://stat.customs.ru. Дата обращения: 26.02.2020.

\section{References}

1.Modern food is the main cause of fatal diseases [Web resource] URL: http://www.moscowuniversityclub.ru/home. asp?artld=10176. Access date: 26.02.2020 (In Russ.).

2.Sirota S.M., Kononkov P.F. State of production, consumption of vegetables and seed production of vegetable crops. Federal reference list. Moscow, 2009. Pp. 303-310 (In Russ.).

3.Gil' L.S., Pashkovskij A.I., Sulima L.T. Scientists named unexpected consequences of refusing vegetables. Zhitomir: Ruta, 2012. 468 p. (In Russ.).

4.Evgen'eva N. Scientists named unexpected consequences of refusing vegetables [Web resource] URL: https://www.msn.com/ruru/foodanddrink/foodculture. Access date: 26.02.2020 (In Russ.).

5.Ludilov V.A. et al. Nutritional value of green vegetable crops of cabbage. Nutritional value of green vegetable crops of the Cabbage family. Collection of scientific papers on vegetable and melon growing (to the 80th anniversary of the founding of the ARRIVG RAS). Moscow, 2011. Pp. 401-405 (In Russ.).

6.Newsletter of the WHO [Web resource] URL: https://www.who. int. Access date: 26.02.2020 (In Russ.).

7.Russians consume three times less fruit than they should [Web resource] URL: https://www.newsru.com/finance/09jun2002/fruits. html. Access date: 26.02.2020 (In Russ.).

8.Izvestia newspaper [Web resource] URL: https://www.iz.ru. Access date: 26.02.2020 (In Russ.).

9.Fruit and vegetable consumption in Russia and Europe [Web resource] URL: http://go-veg.ru/vegetables-norm. Access date: 26.02.2020 (In Russ.).

10. Consumption of fresh vegetables and fruits [Web resource] URL: https://www.marketing.spb.ru/mr/food. Access date: 26.02.2020 (In Russ.).

11. Gnedkov S., Morozova A. Overview of the Moscow market of vegetables and fruits. Russian food market [Web resource] URL: http://www.foodmarket.spb.ru/archive.php. Access date: 26.02.2020 (In Russ.).

12.The school of investor [Web resource] URL: http:// investorschool.ru/economica. Access date: 26.02.2020 (In Russ.).

13. Russia in numbers. 2019 [Web resource] URL: http://www. gks.ru/wps/wcm/connect/rosstat_main/rosstat/ru/statistics/ publications/catalog. Access date: 26.02.2020 (In Russ.).

14.Djatlovskaja E. In 2019 the harvest of greenhouse vegetables will grow to 1.3 million tons [Web resource] URL: https://www. agroinvestor.ru/analytics/news. Access date: 26.02.2020 (In Russ.). 15. Indicators that characterize import substitution in Russia [Web resource] URL: http://www.gks.ru/wps/wcm/connect/rosstat main/rosstat/ru. Access date: 26.02.2020 (In Russ.).

16.Customs statistics of foreign trade [Web resource] URL: http:// stat.customs.ru. Access date: 26.02.2020 (In Russ.).

\section{Об авторах}

Сирота Сергей Михайлович, доктор с.-х. наук, зам. директора по семеноводству и коммерческой деятельности. E-mail: sirota@vniissok.ru

Пинчук Елена Владимировна, канд. с.-х. наук, с.н.с. лаборатории новых технологий

Шевченко Татьяна Егоровна, н.с. лаборатории новых технологий

ФГБНУ Федеральный научный центр овощеводства (ФГБНУ ФНЦО)

\section{Author details}

Sirota S.M., Doctor Sci. (Agr.), Deputy Director for seed production and commercial activities. E-mail: sirota@vniissok.ru

Pinchuk E.V., Cand. Sci. (Agr.), senior research fellow, laboratory of new technologies

Shevchenko T.E., research fellow, laboratory of new technologies FSBSI Federal Scientific Centre of Vegetable Growing (FSBSI FSCVG) 